\title{
Prevalence and associated risk factors for childhood strabismus in Lhasa, Tibet, China: a cross-sectional, school-based study
}

\author{
Hailong $\mathrm{He}^{1,2}$, Jing Fu ${ }^{1 *} \mathbb{D}$, Zhaojun Meng ${ }^{1}$, Weiwei Chen ${ }^{1,2}$, Lei Li ${ }^{1}$ and Xinyu Zhao ${ }^{3}$
}

\begin{abstract}
Background: To estimate the prevalence of strabismus and associated risk factors among grade one school children in Lhasa, Tibet, China.

Methods: The Lhasa Childhood Eye Study (LCES) was a cross-sectional, school-based childhood study conducted in Grade one students from primary schools in Lhasa, Tibet, China. Comprehensive ophthalmic examinations and basic systemic examinations were evaluated. A questionnaire survey containing information about children, as well as parents' information, was sent to the corresponding parents of eligible children. The prevalence of strabismus and its $95 \%$ confidence interval was estimated. Univariate and multivariate logistic regression analyses were conducted to determine the associated risk factors.
\end{abstract}

Results: A total of 1942 eligible grade one students were enrolled, of which 1856 participants completed all examinations. The average age was $6.83 \pm 0.46$ years, $53 \%$ of participants were boys and 1762 were the Tibetan Minority. Over all, the prevalence of strabismus was $68 / 1856$ (3.7\%) (95\%Cl: $2.81,4.52)$, with no difference between the ages, genders, ethnicities and body mass index, while tilting one's head when writing may be a risk factor for strabismus $(P=0.004)$. Strabismus students had mean best corrected visual acuity of $0.16 \pm 0.28($ LogMAR), over $50 \%$ patients with esotropia were hyperopic, and participants who had stereopsis impairments showed a significant difference between esotropia and exotropia $(P=0.026)$.

Conclusions: The prevalence of strabismus in LCES was 3.7\%, which is higher than previous reports from Chinese childhood epidemiology studies. Strabismus is a common contributing factor to amblyopia. Tilting one's head when writing may be a risk factor. Esotropia is more likely to affect stereopsis and be associated with the refractive state of hyperopia.

Trial registration: The study has finished the clinical registration on Chinese Clinical Trial Registry. (http://www. chictr.org.cn, ChiCTR1900026693).

Keywords: Strabismus, Prevalence, Children, Epidemiology

\footnotetext{
* Correspondence: fu_jing@126.com

${ }^{1}$ Beijing Tongren Eye Center, Beijing Tongren Hospital, Capital Medical University; Beijing Ophthalmology \& Visual Sciences Key Laboratory, No.1, Dong Jiao Min Xiang Street, Dongcheng District, Beijing 100730, China

Full list of author information is available at the end of the article
} 


\section{Background}

Strabismus, also called squint, is a condition of misalignment of the visual axes of the eyes, and was first known as eye misalignment since the Hippocratic era [1]. It can adversely affect not only binocular single vision, like simultaneous perception, fusion and stereopsis, but also cosmetic impairment, which can cause significant psychosocial consequences [2, 3] Strabismus is a common contributing factor to amblyopia in children, which will persist into adulthood if not treated in time [4]. Hence, early detection and treatment should be considered for strabismus and amblyopia, especially in preschool children, to maximize binocular potential and to improve outcomes $[5,6]$.

An accurate epidemiology of disease will help in evaluating the screening results, improving effective treatment strategies and guiding the allocation of medical resources [7]. However, although the prevalence of strabismus in school-based studies have been estimated in recent years, the prevalence of various studies differs. Screening for eye diseases in school-aged children has largely been done in large cities, with very few information available in remote areas, like Tibet at a highaltitude plateau area. Impaired vision in early childhood can have a profound impact on a child's development. Screening in childhood has become an important part of the children's eye health program and should be done early $[8,9]$.

Tibet is a region in Asia covering much of the Tibetan Plateau, with an average elevation of $5000 \mathrm{~m}$. The atmospheric conditions are hypobaric, with thin air, high numbers of sunshine hours and strong ultraviolet radiation [10]. To our knowledge, although some epidemiological surveys of common eye diseases have been carried out in recent years, they lacked longitudinal investigation on eye diseases of school-age children in the Tibetan plateau areas [11]. The purpose of this survey was to assess the prevalence and progressive nature of strabismus in native Tibetan children, to determine its associated risk factors and to evaluate the demand for eye care service in Lhasa Prefecture, Tibet Autonomous Region, China.

\section{Methods}

\section{Study design}

The Lhasa Childhood Eye Study (LCES) was a crosssectional, school-based, longitudinal cohort study conducted in Lhasa, Tibet, China. The study was mainly designed to estimate the prevalence and associated risk factors of ocular diseases in school-age children during a 5-year follow-up (Chinese Clinical Trial Registry [ChiCTR], Identifier: ChiCTR1900026693). Ethics committee approval was obtained from the Institutional Review Board of Beijing Tongren Hospital, Capital Medical University (TRECKY2019-146) in accordance with the
Declaration of Helsinki principles. The first visit of LCES was between September 2019 to October 2019. Written informed consent forms were obtained and signed by all parents or guardians before the examinations. The procedures were modified from the Anyang childhood eye Study (ACES) conducted in central China [12].

\section{Participants}

There are in total 28 elementary schools in Lhasa. Officials from the health and education departments of Lhasa summoned the principals of the 28 schools before recruitment, to inform them the LCES would be conducted from 2019 to 2024 . Twenty-seven out of the 28 elementary schools in Lhasa were available to join and were stratified into three levels based on the evaluation of local government. Voluntary Grade one students who had been living in Lhasa city for at least half a year and would continue to live there for at least 5 years until they enter different middle schools were included in LCES. Individuals suffering from mental illness or other medical conditions who were unable to cooperate with the baseline survey were excluded. According to geographical characteristics and required sample size, 1943 Grade one students of seven primary schools were randomly sampled by stratified cluster sampling. All the clusters were numbered according to their locations and were randomly selected using a random numbers table. Participants were followed for 5 years until they entered different middle schools and could withdraw from the study at anytime for any reason.

\section{Parental questionnaire}

The questionnaires were mainly derived from the version of that used in the ACES [12] and were modified to make sure the questionnaires were culturally appropriate and linguistically accurate. The questionnaire contained information about indoor and outdoor activity, history of the birth and ophthalmic treatment, and habits of reading, writing, living, eating and so on, as well as parents' information such as refractive and socioeconomic status, education, pregnancy history, medical records and other aspects. For example, the questionnaire would ask 1)'What is your child's current preferred writing posture?' and 2)'As far as you remember, did your child prefer to tilt his head when he/she was writing?' with the following options: Yes or NO or Not sure.

\section{Procedures}

\section{Systemic examinations}

Blood pressure and heart rate were measured using a digital automatic blood pressure monitor (HK-808, HSH, Shenzhen, China). Oxygen saturation was measured using a digital fingertip pulse oximeter (YX301, YUWELL, Jiangsu, China). Height and weight (without 
shoes or heavy clothing) were determined using a weighing scale. Body Mass Index (BMI, BMI $=$ weight $/$ height $^{2}$ $\mathrm{kg} / \mathrm{m}^{2}$ ) was also calculated.

\section{Ophthalmic examinations}

The comprehensive eye examination was performed by a team of two optometrists and four ophthalmologists from Beijing Tongren Hospital who were trained and certified using standardized study protocols.

\section{Distant and near visual acuity}

Uncorrected and presenting distant visual acuity (VA) were measured for the right eye and left eye using Lea Symbols ETDRS $3 \mathrm{~m}$ set charts $(250,300$, Goodlite, IL, USA) at a distance of $3 \mathrm{~m}$ based on the instructions and standard procedure. The last line attempted, combined with the number of mistakes made on that and previous lines, was used to calculate a letter-by-letter $\operatorname{logMAR}$ VA score. Pinhole and best-corrected distant VA (BCVA) were obtained after subjective refraction test for students with uncorrected distance $\mathrm{VA}<20 / 20$ ( $>$ LogMAR 0.0).

\section{Refraction}

Objective refraction was measured before and after cycloplegia using an autorefractor (KR-800, Topcon, Tokyo, Japan). The cycloplegic procedure for each student was to first administer one drop of topical anesthetic agent (Alcaine, Alcon), followed by two drops of $1 \%$ cyclopentolate (Alcon) and one drop of Mydrin P (Santen, Japan) given 5 min separately. Thirty minutes after the last drop was instilled, a third drop of cyclopentolate was administered if the pupillary light reflex was still present or the pupil size was less than $6.0 \mathrm{~mm}$.

\section{Ocular movements}

Nine directions of gaze including primary, secondary and tertiary were examined and recorded by asking students to fix on a moving penlight without moving their heads.

\section{Ocular dominance}

Students were asked to hold a card with a central hole and fixate on a distant object while holding their head stationary. The examiner covered the students' eyes one after the other and repeated it three times to determine the dominant eye.

\section{Cover test}

Unilateral and alternating cover tests were performed at far $(6 \mathrm{~m})$ and near $(33 \mathrm{~cm})$ to detect heterotropia and heterophoria by an experienced pediatric ophthalmologist under natural conditions (with and without spectacles), respectively, and the magnitude of the deviation was measured using loose prisms. The prism was placed with the base along the reversed direction of deviation and was adjusted until no movement could be detected.

\section{Stereopsis}

Stereo Fly Test (S0001, STEREO, USA) was used to quantitatively measure stereo acuity for students at 40 $\mathrm{cm}$.

\section{Diseases definition and classification}

Strabismus was defined if any heterotropia was present at near or distance, with or without spectacles and then classified according to the primary direction of the tropia [13].

Depending upon the clinic-etiological features, primary exotropia was classified into basic non-specific type (exotropia approximately equal for near and distance), convergence insufficiency type (exotropia greater for near than distance, $\geq 10$ prism diopters [PD]), and divergence excess (exotropia greater for distance than near, $\geq 10 \mathrm{PD}$ ). Esotropia was classified into accommodative esotropia (due to overaction of convergence associated with accommodation reflex) and non-accommodative esotropia (all those primary esodeviations in which the amount of deviation is not affected by the state of accommodation and roughly equal in amount at distance and near fixation) [14].

Micro-strabismus was defined as a deviation of $<10$ PD in the presence of demonstrable binocular vision on the Lang II test. In the absence of demonstrable binocular vision, a deviation of this magnitude was classified simply as strabismus [15].

\section{Statistical analysis}

The prevalence of strabismus was calculated and analyzed as the percentile of the number of individuals with different types of strabismus to the total number of individuals evaluated. Continuous variables were given as the mean \pm standard deviation (SD), and categorical variables were given as the absolute value and relative frequency. Prevalence of strabismus and its 95\% confidence interval (CI) was estimated using a general linear model. Risk factors associated with high level strabismus were evaluated using a linear regression model. The potential risk factors including general characters like age, gender, ethnicity, BMI, heart rate, oxygen saturation, and habits of reading, living, eating, as well as parents' information such as pregnancy history and so on. The analyses were implemented with SAS software version 9.4 (SAS institute Inc. Cary, NC). $x^{2}$ tests and $t$-tests were also used. A $p$-value of $<0.05$ was considered statistically significant. 


\section{Results}

\section{General information}

A total of 1942 Grade one students were enrolled, of which 1902 (97.94\%) were eligible for LCES according to the inclusion and exclusion criteria. A subset of 1856 of the remaining eligible individuals completed all examinations, giving a response rate of $97.58 \%$. For the entire group of analyzable participants, 1762 (94.93\%) students were the Tibetan Minority, 85 (4.58\%) were Han Majority and nine $(0.49 \%)$ were other minority nationalities. The average age was $6.83 \pm 0.46$ years and 984 (53.02\%) of the participants were boys (Table 1). The mean BCVA measured by LogMAR was $0.05 \pm 0.11$ and $0.05 \pm 0.10$ for right and left eye, respectively. Cycloplegic spherical equivalent (SE) was $+1.07 \pm 0.92$ diopters (D). 1192 (64.22\%) of the participants' ocular dominance eyes were right eyes, 664 were left eye dominant, and none of them showed no dominance preference.

\section{Prevalence of strabismus}

Based on the comprehensive eye examinations of the 1856 Grade one students, the overall prevalence of strabismus was $3.66 \%$ (95\%CI, 2.81-4.52\%). Of the 68 students with strabismus, the most frequent form of strabismus was exotropia ( $n=43,2.32 \%)$, followed by eight $(0.43 \%)$ with esotropia, with an exotropia: esotropia ratio of 5.38:1, two
(0.11\%) with microtropia (one esotropia and one exotropia), eight $(0.43 \%)$ with vertical deviation combining horizontal strabismus, seven $(0.38 \%)$ with exotropia combining superior oblique muscle paralysis (SOP), and one $(0.05 \%)$ with exotropia combining double depressor paralysis (DDP). Three cases $(0.16 \%)$ had pure vertical strabismus, and all of these had SOP. Four (0.22\%) special strabismus cases were diagnosed. Two had Duane's retraction syndrome, one had dissociated vertical deviation (DVD) combining oblique muscle dysfunction and one had nystagmus due to congenital cataract (Table 2). The magnitude of exotropia and esotropia is shown in Fig. 1 and Fig. 2. Eleven students (16.18\%) with strabismus also had amblyopia; eight (11.76\%) were esotropia, two were exotropia and one was vertical deviation combining horizontal strabismus.

There was no significant difference of BCVA between the two eyes $(P=0.59)$ for the entire group. The mean BCVA of the strabismus $(0.16 \pm 028)$ and nonstrabismus $(0.04 \pm 0.09)$ children had significant difference $(P=0.0008)$. Among 1192 participants' with righteye dominance, there were 40 with strabismus, while in the 664 left-eye dominant eyes, there were 28 with strabismus. The effect of ocular dominance between strabismus and non-strabismus patients was not statistically significant $(P=0.34)$.
Table 1 Characteristics of participants of LCES $(N=1856)$

\begin{tabular}{|c|c|}
\hline Items & Values \\
\hline Age, years (mean $\pm s d)$ & $6.83 \pm 0.46$ \\
\hline \multicolumn{2}{|l|}{ Gender, $n(\%)$} \\
\hline Boy & $984(53 \%)$ \\
\hline Girl & $872(47 \%)$ \\
\hline \multicolumn{2}{|l|}{ Ethnic categories, $n(\%)$} \\
\hline Tibetan Minority & $1762(94.9 \%)$ \\
\hline Han Majority & $85(4.6 \%)$ \\
\hline Others Majorities & $9(0.5 \%)$ \\
\hline Height, cm, (mean \pm sd) & $120.55 \pm 5.52$ \\
\hline Weight, kg, (mean \pm sd) & $22.96 \pm 3.69$ \\
\hline $\mathrm{BMI}, \mathrm{kg} / \mathrm{m}^{2},($ mean $\pm \mathrm{sd})$ & $15.74 \pm 1.80$ \\
\hline Heart rate, beat, (mean \pm sd) & $95.27 \pm 14.27$ \\
\hline Oxygen saturation, \%, (mean $\pm \mathrm{sd})$ & $92.68 \pm 3.07$ \\
\hline \multicolumn{2}{|l|}{ BCVA, LogMAR, (mean \pm sd) } \\
\hline Right eyes & $0.05 \pm 0.11$ \\
\hline Left eyes & $0.05 \pm 0.10$ \\
\hline Cycloplegic SE, D, (mean \pm sd) & $+1.07 \pm 0.92$ \\
\hline \multicolumn{2}{|l|}{ Ocular dominance eyes, n(\%) } \\
\hline Right eyes & $1192(64.2 \%)$ \\
\hline Left eyes & $664(35.8 \%)$ \\
\hline
\end{tabular}

Table 2 Prevalence of strabismus and subtypes $(N=1856)$

\begin{tabular}{ll}
\hline Classification & $\boldsymbol{n}(\%)$ \\
\hline Exotropia & $43(2.3)$ \\
Basic non-specific type & $31(1.7)$ \\
Divergence excess & $1(0.1)$ \\
Convergence insufficiency type & $11(0.6)$ \\
Esotropia & $8(0.4)$ \\
Accommodative esotropia & $5(0.3)$ \\
Non-accommodative esotropias & $1(0.1)$ \\
Others & $2(0.1)$ \\
Vertical deviation combining horizontal strabismus & $8(0.4)$ \\
Exotropia combining SOP & $7(0.4)$ \\
Exotropia combining DDP & $1(0.1)$ \\
Vertical strabismus & $3(0.2)$ \\
SOP & $3(0.2)$ \\
Microtropia & $2(0.1)$ \\
Others & $4(0.2)$ \\
Duane syndrome & $2(0.1)$ \\
DVD combining oblique muscle dysfunction & $1(0.1)$ \\
Nystagmus for congenital cataract & $1(0.1)$ \\
Total & $68(3.7 \%)$ \\
\hline
\end{tabular}




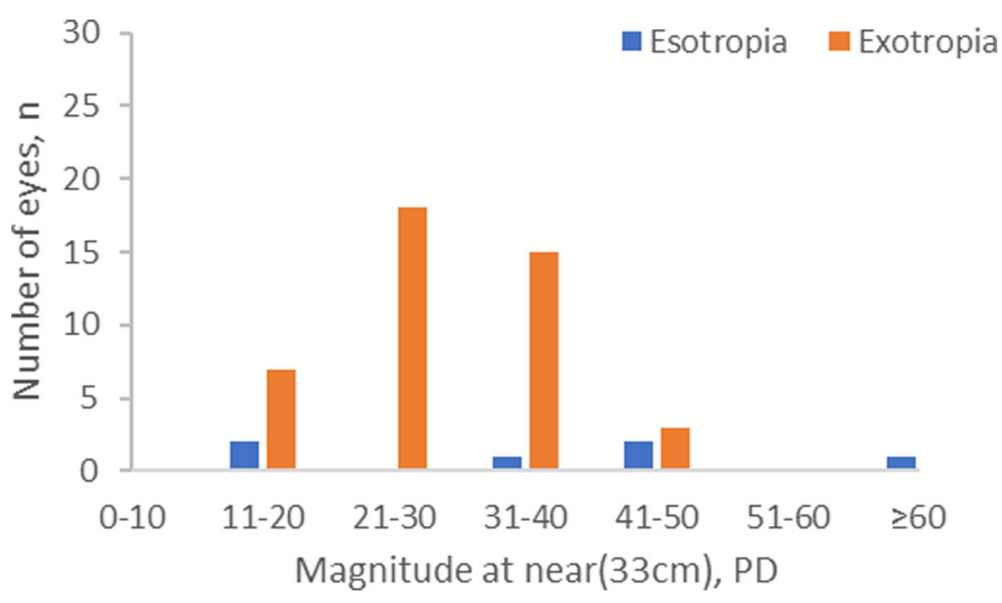

Fig. 1 Distribution of the magnitude of exotropia and esotropia at $33 \mathrm{~cm}$

\section{Risk factors related to strabismus}

Table 3 shows the risk factors associated with strabismus. Tilting one's head when writing $(P=0.004)$ had inverse relationships with the prevalence of strabismus. The odds of strabismus with incorrect writing posture was 1.58 (95\% CI:1.16-2.15) times more than correct writing posture, defined as keeping the head in a plane perpendicular to the ground. The effects of age, sex, and ethnicity were not statistically significant $(P>0.05)$. In multiple logistic regression for strabismus, writing posture was statistically significant in strabismus subjects (OR1.5; 95\% CI, 1.07-2.08), with a higher prevalence of strabismus with incorrect writing posture (tilting one's head) when writing.

\section{Refractive status}

Among the 1856 Grade one students examined, 1853 (99.84\%) had cycloplegic autorefraction performed on both eyes. The mean cycloplegic SE of the right and left eyes for horizontal strabismus were $+1.24 \pm 1.49 \mathrm{D}$ and +
$1.21 \pm 1.33 \mathrm{D}$ respectively, with no significant difference $(P=0.89)$. The prevalence rates of emmetropia (between $-0.50 \mathrm{D}$ and $+2.00 \mathrm{D}$ in both eyes) were $89.15 \%$ based on right eye data. The mean cycloplegic SE of esotropia students was +2.05D compared with +1.09D in exotropia students; the difference was statistically significant $(P<$ 0.05 ). Figure 3 outlines the cycloplegic SE of esotropia and exotropia students.

\section{Stereopsis}

Stereopsis acuity and deviation angle were further evaluated in 49 esotropia and exotropia participants. The mean deviation angle of four participants with impaired stereopsis vision was $35.00 \pm 17.80 \mathrm{PD}$, and for the remaining 45 participants with normal stereopsis vision, was $33.00 \pm 11.40$ PD. Participants who lack stereopsis vision had significantly larger deviation angles than those who have binocular vision $(P<0.05)$. Participants with stereopsis impairment showed a significant difference

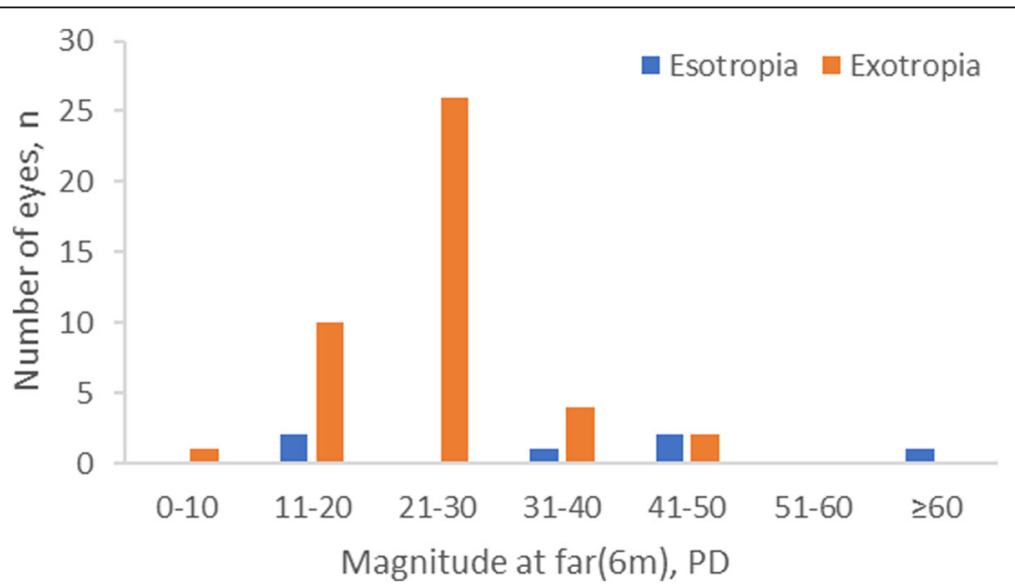

Fig. 2 Distribution of the magnitude of exotropia and esotropia at $6 \mathrm{~m}$ 
Table 3 Risk factors associated with strabismus

\begin{tabular}{lll}
\hline Characters & $\boldsymbol{P}$ & OR(95\%Cl) \\
\hline Age & 0.9865 & $1.00(0.59-1.69)$ \\
Gender & 0.8177 & $0.94(0.58-1.54)$ \\
Ethnic & 0.5948 & $0.56(0.14-2.32)$ \\
Height & 0.5436 & $1.01(0.97-1.06)$ \\
Weight & 0.1509 & $1.04(0.98-1.11)$ \\
BMl & 0.1413 & $1.10(0.97-1.24)$ \\
Heartrate & 0.3455 & $0.99(0.98-1.01)$ \\
Oxygen saturation & 0.9967 & $1.00(0.92-1.08)$ \\
Lamp use & 0.2778 & $0.83(0.59-1.16)$ \\
Writing posture & 0.0040 & $1.58(1.16-2.15)$ \\
Sleep habits & 0.9422 & $1.04(0.32-3.40)$ \\
Pregnancy history & 0.6757 & $1.20(0.51-2.83)$ \\
Fruits intake & 0.8290 & $1.07(0.58-1.96)$ \\
Vegetables intake & 0.7230 & $1.12(0.61-2.04)$ \\
\hline
\end{tabular}

between esotropia $(3 / 8)$ and exotropia $(2 / 43)(P=0.026)$, while esotropia was more likely to affect stereopsis.

\section{Discussion}

To the best of our knowledge, the LCES is the first comprehensive school-based cohort study in the highaltitude plateau Lhasa, Tibet, China and provide baseline data of the Tibetan Minority for epidemiology of Grade one students eye disorders. We found the prevalence of strabismus was $3.66 \%$ with an exotropia: esotropia ratio was 5.38:1, and participants with esotropia were more likely to affect stereopsis, with most being hyperopic.
The overall prevalence of strabismus in our study was higher than previous reports from China and most of other studies around the world. We summarized the previous prevalence of Chinese pediatric strabismus study in Table $4[3,7,16-23]$. The prevalence of strabismus in our study was lower than the 5.65 and $5.8 \%$ in different 3-6-year-old children from the Nanjing Pediatric study [7, 18]; Nanjing is a metropolis in eastern China. Compared with the prevalence from other countries, the prevalence of LCES was higher than the 3.3\% in Caucasian and $2.1 \%$ in African American children in the Baltimore Pediatric Eye Disease Study [24], 2.4\% in Hispanic/Latino and 2.5\% African-American children in the Multi-Ethnic Pediatric Eye Disease Study [25], 1.3\% in Japan [26], 2.4\% in Turkey [27], and $0.8 \%$ in the Strabismus, Amblyopia and Refractive Error in Singaporean Children (STARS) [28].

The higher prevalence of strabismus in LCES may relate to several reasons. Firstly, among the 1856 participants, $94.93 \%$ were native Tibetan Minority. The potential influence of ethnic, environmental, lifestyle and genetic susceptibility differences [16] is still unclear. Qian reported that the prevalence of ocular disease differences in Tibet may relate to more exposure to sunlight and easier schooling [29] Whether Tibetan children have a higher prevalence of strabismus requires further investigation. Secondly, different age ranges across the different studies may play an important role $[3,16]$. The mean age of our voluntary students was $6.83 \pm 0.46$ years, and the age range was narrower than other studies, although, older than the two Nanjing pediatric studies $[7,18]$. Finally, we recruited four professional strabismus and pediatric ophthalmologists to examine the participants. They have professional experience in checking

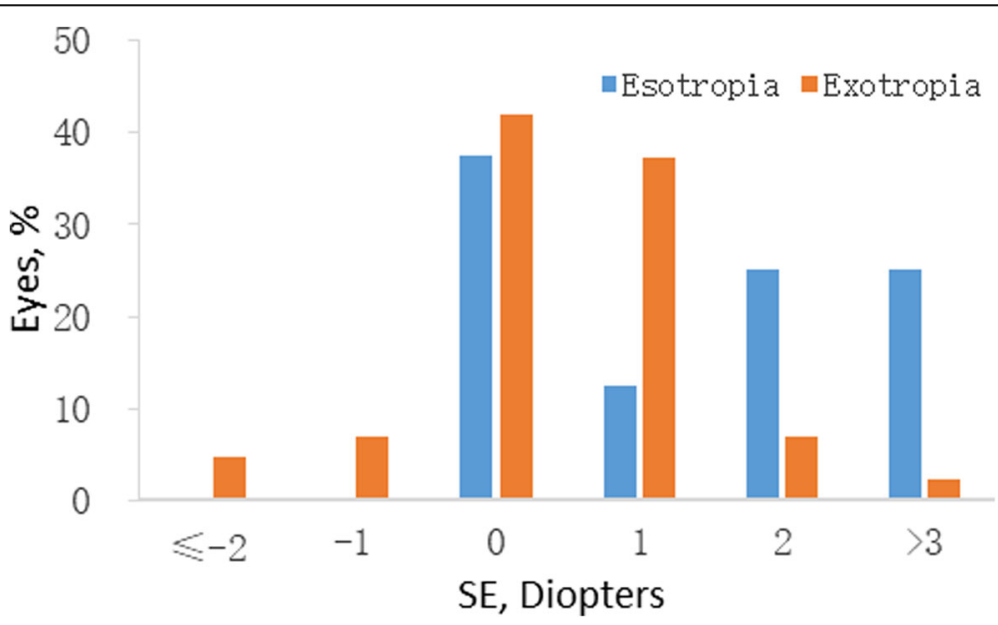

Fig. 3 Distribution of the cycloplegic SE of esotropia and exotropia students (right eyes) 
Table 4 Prevalence of strabismus in previous Chinese studies

\begin{tabular}{|c|c|c|c|c|c|c|}
\hline Author & Year & Area & Samples & Age/years & Prevalence/\% & Exo:Eso \\
\hline \multirow[t]{2}{*}{ Zhu H } & 2019 & Yunnan & 1656 & $7-8$ & 1.50 & 10.6:1 \\
\hline & & & 1394 & $13-14$ & 2.44 & \\
\hline \multirow[t]{3}{*}{ Pan CW } & 2017 & Yunnan & 3122 & $6-8$ & 2.47 & \\
\hline & & & 4305 & $9-11$ & 3.69 & $9.4: 1$ \\
\hline & & & 1836 & $12-14$ & 4.96 & \\
\hline Pan CW & 2016 & Nanjing & 5831 & $3-6$ & 5.8 & / \\
\hline Chen $X$ & 2016 & Nanjing & 5884 & $3-6$ & 5.65 & $6: 1$ \\
\hline \multirow[t]{2}{*}{ Fu J } & 2014 & Anyang & 3112 & $7-8$ & 2.73 & $6: 1$ \\
\hline & & & 2362 & $12-13$ & 5.02 & $51: 1$ \\
\hline Pi LH & 2012 & Chongqing & 3079 & $6-15$ & 0.29 & $1.7: 1$ \\
\hline Lu P & 2008 & Qinghai & 1084 & $6-14$ & 2.49 & $5.7: 1$ \\
\hline $\mathrm{He} \mathrm{M}$ & 2007 & Yangxi & 2454 & $13-17$ & 1.63 & $3.5: 1$ \\
\hline He M & 2004 & Guangzhou & 4364 & $5-15$ & 1.9 & $4: 1$ \\
\hline Zhao J & 2000 & Shunyi & 5884 & $5-15$ & 2.8 & / \\
\hline
\end{tabular}

strabismus, with a likely greater detection rate of less obvious strabismus and mildly impaired visual acuity.

The ratio of exotropia: esotropia ratio in LCES was 5.38:1, which was lower than many studies $[3,7,16-23]$. The reason for this probably relates to the status of refraction; the distribution of the cycloplegic SE of esotropia in LCES tend to be hyperopia, which was consistent with the finding that exotropia was associated with astigmatism, myopia and low to moderate hyperopia, while esotropia was associated with hyperopia in a doseresponse manner [16, 30, 31]. Qian also found that Tibetan adolescents had a lower prevalence of refractive errors than the plains (central China) area except for hyperopia, and also suggested that the rate of hyperopia in Tibet is higher [29]. As we show here, in the present LCES study the prevalence of hyperopia was higher at $6.91 \%$. However, the prevalence of hyperopia was $2.21 \%$ in ACES. Comparing the significant hyperopic prevalence difference between LCES and ACES, this probably explains the discrepancy in the ratio of exotropia: esotropia between the two studies.

Strabismic amblyopia typically influences the dominance of the fixating eye and chronically reduced responsiveness to input by the non-fixating eye [8]. The mean BCVA of the strabismus and non-strabismus eyes showed students with strabismus had worse BCVA. We also found that participants with stereopsis impairment had bigger deviation angles and esotropia was more likely to affect stereopsis. The VA in strabismic amblyopia can be improved after successful treatment in younger ages and stereopsis can be restored after surgical alignment in many strabismus cases [32, 33] The earlier that clinically significant refractive error and strabismus are detected and treated, the greater the likelihood of preventing or reducing amblyopia. 8 However, most children with strabismus and amblyopia in LCES were not diagnosed earlier, let alone treated.

Some studies found higher prevalence of strabismus in older students $[3,16]$. Our study did not find that for students in LCES from Grade 1. However, the age span was not as large as others. The effect of some regional factors like oxygen saturation and ethnicity characters were not statistically significant likewise, which is in agreement with the previous study [16]. Dietary (fruits and vegetables) intake did not influence the prevalence of strabismus, either. Tilting one's head when writing was a risk factor for the prevalence of strabismus. In a forward multiple logistic regression for strabismus, writing posture was statistically significant, reflecting a higher prevalence of strabismus with habits like tilting one's head when writing. Bao and co-authors reported that the near heterophoria state can affect near vision posture, while head tilt angle and ocular gaze angle had a potential relationship with strabismus [34]. However, it is possible that head tilt may have developed because of strabismus, and can be accepted as a sign of misalignment. Hence, although we consider that tilting one's head when writing may be a risk factor for the prevalence of strabismus, it requires further research to verify or refute this observation.

There are some limitations to the present study. Some risk factors might be potentially inaccurate due to the self-reported questionnaires from the students' parents, even though the questionnaires used in the LCES were calibrated for cultural differences. In addition, strabismus history and treatment were not always remembered by their parents clearly, which could lead to a misestimate for prevalence of strabismus. 


\section{Conclusion}

As the first comprehensive school-based cohort study in Tibet, the LCES had high response rate and good comparability with other studies. Moreover, the LCES study is the first longitudinal study on childhood ocular diseases in plateau regions of Chinese children and will continue follow-up for 5 years and could provide invaluable ophthalmic baseline data for this population and worldwide eye care.

\section{Supplementary Information}

The online version contains supplementary material available at https://doi. org/10.1186/s12886-020-01732-2.

\section{Additional file 1.}

\section{Abbreviations}

LCES: The Lhasa Childhood Eye Study; ACES: The Anyang Childhood Eye Study; BMI, BMl: weight/height ${ }^{2} \mathrm{~kg} / \mathrm{m}^{2}$ Body Mass Index; BCVA: Best-corrected visual acuity; SE: Spherical equivalent; SOP: Superior oblique muscle paralysis; DDP: Double depressor paralysis; DVD: Dissociated vertical deviation; STARS: The Strabismus, Amblyopia and Refractive Error in Singaporean Children; SD: Standard deviation; Cl: Confidence interval; PD: Prism diopters

\section{Acknowledgements}

The authors are grateful for the support from the Lhasa city government and the Beijing Hoson Foundation for helping organize the epidemiology study.

\section{Authors' contributions}

J F, HL H and WW C initiated the study design. ZJ M, L L and XY Z prepared the consent form. HL H and J F drafted and finalized the study protocol. All authors reviewed the study protocol and approved the final manuscript.

\section{Funding}

The LECS is supported by the Capital Health Development Special Fund of China -Major Project (SF-2018-1-2051), Youth Project (2018-4-1083):design of the study;

The LECS is supported by High Level Health Technical Talent Training Program of Beijing Municipal Health Bureau (2015-3-023), Beijing Municipal Science \& Technology Commission (Z171100001017066): collection, analysis, and interpretation of data and in writing the manuscript

\section{Availability of data and materials}

The datasets used and/or analysed during the current study available from the corresponding author on reasonable request.

\section{Ethics approval and consent to participate}

Ethics committee approval was obtained from the Institutional Review Board of Beijing Tongren Hospital, Capital Medical University (TRECKY2019-146) in accordance with the Declaration of Helsinki principles. Written informed consent forms were obtained and signed by all parents or guardians before the examinations.

\section{Consent for publication}

The authors declare that they agree to publish.

\section{Competing interests}

The authors declare that co-author 'Weiwei Chen' is the member of Editorial Board in this section.

\section{Author details}

'Beijing Tongren Eye Center, Beijing Tongren Hospital, Capital Medical University; Beijing Ophthalmology \& Visual Sciences Key Laboratory, No.1, Dong Jiao Min Xiang Street, Dongcheng District, Beijing 100730, China. ${ }^{2}$ Beijing Institute of Ophthalmology, Beijing, China. ${ }^{3}$ Department of Epidemiology and Biostatistics, Institute of Basic Medical Sciences Chinese
Academy of Medical Sciences, School of Basic Medicine Peking Union Medical College, Beijing, China.

Received: 7 May 2020 Accepted: 12 November 2020

Published online: 25 November 2020

\section{References}

1. Tsoucalas G, Papaioannou T, Karamanou M. Michael Constantine Psellus (1020-1105 AD) and his definitison of strabismus. Strabismus. 2018;26(3): $155-7$.

2. Read JC. Stereo vision and strabismus. Eye (Lond). 2015;29(2):214-24.

3. Fu J, Li SM, Liu LR, et al. Prevalence of amblyopia and strabismus in a population of 7th-grade junior high school students in Central China: the Anyang childhood eye study (ACES). Ophthalmic Epidemiol. 2014;21(3):197-203.

4. Pediatric Eye Disease Investigator Group. A comparison of atropine and patching treatments for moderate amblyopia by patient age, cause of amblyopia, depth of amblyopia, and other factors. Ophthalmology. 2003; 110(8):1632-7.

5. Jost RM, Yanni SE, Beauchamp $\mathrm{CL}$, et al. Beyond screening for risk factors objective detection of strabismus and amblyopia. JAMA Ophthalmol. 2014; 132(7):814-20

6. Lekskul A, Supakitvilekarn T, Padungkiatsagul T. Outcomes of undercorrection in surgical management and binocular vision gained of adult intermittent exotropia. Clin Ophthalmol. 2018:12:1763-7.

7. Chen X, Fu Z, Yu J, et al. Prevalence of amblyopia and strabismus in eastern China: results from screening of preschool children aged 36-72 months. $\mathrm{Br}$ Ophthalmol. 2016;100(4):515-9.

8. Wallace DK, Repka MX, Lee KA, et al. Amblyopia preferred practice pattern ${ }^{\circledast}$. Ophthalmology. 2018;125(1):P105-42.

9. Mettla AL, Marmamula S, Khanna RC. Children's eye health programmes: successful strategies and challenges. Commun Eye Health. 2017;30(98):S28-30.

10. Bali J, Chaudhary KP, Thakur R. High altitude and the eye: a case controlled study in clinical ocular anthropometry of changes in the eye. High Alt Med Biol. 2005;6(4):327-38.

11. Wang GQ, Bai ZX, Shi J, Luo S, Chang HF, Sai XY. Prevalence and risk factors for eye diseases, blindness, and low vision in Lhasa, Tibet. Int J Ophthalmol. 2013;6(2):237-41.

12. Li SM, Liu LR, Li SY, et al. Design, methodology and baseline data of a school-based cohort study in Central China: the Anyang childhood eye study. Ophthalmic Epidemiol. 2013;20(6):348-59.

13. Huang $\mathrm{D}$, Chen $\mathrm{X}$, Zhu H, et al. Prevalence of amblyopia and its association with refraction in Chinese preschool children aged 36-48 months. $\mathrm{Br} J$ Ophthalmol. 2018;102(6):767-71.

14. Wallace DK, Christiansen SP, Sprunger DT, et al. Esotropia and Exotropia preferred practice pattern ${ }^{\oplus}$. Ophthalmology. 2018;125(1):P143-83.

15. Yu CB, Fan DS, Wong WW, Wong CY, Lam DS. Changing patterns of strabismus: a decade of experience in Hong Kong. Br J Ophthalmol. 2002; 86(8):854-6.

16. Zhu H, Pan C, Sun Q, et al. Prevalence of amblyopia and strabismus in Hani school children in rural Southwest China: a cross-sectional study. BMJ Open. 2019;9(2):e025441

17. Pan CW, Chen $\mathrm{X}$, Zhu H, et al. School-based assessment of amblyopia and strabismus among multiethnic children in rural China. Sci Rep. 2017;7(1): 13410.

18. Pan CW, Zhu H, Yu JJ, et al. Epidemiology of intermittent Exotropia in preschool children in China. Optom Vis Sci. 2015;93(1):57-62.

19. Pi LH, Chen $L$, Liu $Q$, et al. Prevalence of eye diseases and causes of visual impairment in school-aged children in Western China. J Epidemiol. 2012; 22(1):37-44

20. Lu P, Chen X, Zhang W, et al. Prevalence of ocular disease in Tibetan primary school children. Can J Ophthalmol. 2008:43(1):95-9.

21. He M, Huang W, Zheng Y, Huang L, Ellwein LB. Refractive error and visual impairment in school children in rural southern China. Ophthalmology. 2007;114(2):374-82.

22. He M, Zeng J, Liu Y, Xu J, Pokharel GP, Ellwein LB. Refractive error and visual impairment in urban children in southern China. Invest Ophthalmol Vis Sci. 2004:45(3):793-9.

23. Zhao J, Pan X, Sui R, Munoz SR, Sperduto RD, Ellwein LB. Refractive error study in children: results from Shunyi District, China. Am J Ophthalmol. 2000;129(4):427-35. 
24. Friedman DS, Repka MX, Katz J, et al. Prevalence of amblyopia and strabismus in white and African American children aged 6 through 71 months the Baltimore pediatric eye disease study. Ophthalmology. 2009; 116(11):2128-34

25. Multi-ethnic Pediatric Eye Disease Study Group. Prevalence of amblyopia and strabismus in African American and Hispanic children ages 6 to 72 months the multi-ethnic pediatric eye disease study. Ophthalmology. 2008; 115:1229-36.

26. Matsuo T, Matsuo C. The prevalence of strabismus and amblyopia in Japanese elementary school children. Ophthalmic Epidemiol. 2005;12:31-6.

27. Caca I, Cingu AK, Sahin A, et al. Amblyopia and refractive errors among school-aged children with low socioeconomic status in southeastern Turkey. J Pediatr Ophthalmol Strabismus. 2013;50:37-43.

28. Chia A, Dirani M, Chan YH, et al. Prevalence of amblyopia and strabismus in young Singaporean Chinese children. Invest Ophthalmol Vis Sci. 2010;51(7): 3411-7.

29. Qian X, Liu B, Wang J, et al. Prevalence of refractive errors in Tibetan adolescents. BMC Ophthalmol. 2018;18(1):118.

30. Zhu H, Yu JJ, Yu RB, et al. Association between childhood strabismus and refractive error in Chinese preschool children. PLoSOne. 2015;10:e0120720.

31. Matsuo T, Matsuo C. Comparison of prevalence rates of strabismus and amblyopia in Japanese elementary school children between the years 2003 and 2005. Acta Med Okayama. 2007;61(6):329-34.

32. Iordanous Y, Mao A, Makar I. Preoperative factors affecting stereopsis after surgical alignment of acquired partially accommodative Esotropia. Strabismus. 2015;23(4):151-8.

33. Kurup SP, Barto HW, Myung G, Mets MB. Stereoacuity outcomes following surgical correction of the nonaccommodative component in partially accommodative esotropia. J AAPOS. 2018;22(2):92-6.

34. Bao J, Wang Y, Zhuo Z, et al. Influence of progressive addition lenses on reading posture in myopic children. Br J Ophthalmol. 2016;100(8):1114-7.

\section{Publisher's Note}

Springer Nature remains neutral with regard to jurisdictional claims in published maps and institutional affiliations.

Ready to submit your research? Choose BMC and benefit from:

- fast, convenient online submission

- thorough peer review by experienced researchers in your field

- rapid publication on acceptance

- support for research data, including large and complex data types

- gold Open Access which fosters wider collaboration and increased citations

- maximum visibility for your research: over $100 \mathrm{M}$ website views per year

At $\mathrm{BMC}$, research is always in progress.

Learn more biomedcentral.com/submissions 